\title{
AVALIAÇÃO DE DIFERENTES METODOLOGIAS DE IMOBILIZAÇÃO DE LIPASES COMERCIAIS EM ARGILA MONTMORILLONITA VISANDO APLICAÇÃO NA SÍNTESE DE TRIGLICERÍDEOS DIETÉTICOS
}

\author{
L. F. ALVES ${ }^{1}$, M. P. REINA ${ }^{1}$, A. J. SCHWANKE ${ }^{2}$, S. PERGHER ${ }^{2}$, R. MONTI ${ }^{1}$, A. B. \\ $\mathrm{NETO}^{1}$, A. V. PAULA ${ }^{1}$ \\ ${ }^{1}$ Universidade Estadual Paulista, Faculdade de Ciências Farmacêuticas \\ ${ }^{2}$ Universidade Federal do Rio Grande do Norte, Centro de Ciências Exatas e da Terra \\ E-mail para contato: laura.fio.alves@gmail.com
}

RESUMO - Lipases são enzimas que apresentam capacidade de catalisar reações de hidrólise e síntese de triglicerídeos (TAG). Apesar de possuírem alto custo comercial, o que constitui um obstáculo para sua aplicação, nos últimos anos, a utilização de enzimas imobilizadas ganhou espaço por apresentarem vantagens no uso dos biocatalisadores. Assim, neste trabalho, foram realizadas imobilizações das lipases de Rhizopus oryzae, Aspergillus niger e Mucor javanicus, em suporte argila montmorillonita, empregando-se diferentes metodologias de imobilização (adsorção física e ligação covalente), a fim de avaliar os melhores para futuramente aplicar na síntese de TAG dietéticos. Os derivados imobilizados obtidos foram avaliados quanto à atividade hidrolítica, de esterificação e rendimento de imobilização. Os melhores resultados de imobilização obtidos foram os de adsorção física das lipases de Rhizopus oryzae e Mucor javanicus, as quais apresentaram rendimentos de imobilização de $25,34 \pm 1,03 \%$ e $23,70 \pm 1,09 \%$, respectivamente. Com isso, este trabalho pôde contribuir para o desenvolvimento de tecnologias nacionais de processos enzimáticos e mostrar o potencial da aplicação de suportes alternativos para imobilização de lipases comerciais.

\section{INTRODUÇÃO}

As lipases (triacilglicerol-acil-hidrolases E.C.3.1.1.3) são um grupo de enzimas que catalisam diversas reações envolvendo triacilgliceróis (TAG), tais como sua hidrólise total ou parcial, esterificação, transesterificação e interesterificação, sendo amplamente utilizadas em processos industriais com fins biotecnológicos (Colla et al., 2013). Com relação à especificidade, as lipases são classificadas em lipases não-específicas, as quais catalisam as reações nas posições 1,2 e 3 do TAG de forma aleatória, e lipases 1,3-específicas, atuando nas posições 1 e 3 do TAG, o que proporciona a formação de produtos diferentes das obtidas por lipases não-específicas (Campos, 2010). 
Estas enzimas podem ser obtidas de diferentes fontes. Entre elas, os microrganismos são as principais para aplicação industrial devido à facilidade de obtenção e produção do biocatalisador, a existência de muitos microrganismos produtores e, além disso, a capacidade de realizar modificações genéticas, as quais podem melhorar as características e otimizar a produção da enzima (Campos, 2010).

Os processos industriais têm utilizado biocatalisadores imobilizados em substituição aos livres por proporcionarem possibilidade da aplicação em reatores contínuos, maior estabilidade enzimática, facilidade na separação entre produto e enzima, e, consequentemente, redução dos custos (Coelho et al., 2008; Aires-Barros e Fernandes, 2003). Há grande variedade de suportes (orgânicos ou inorgânicos, sintéticos ou naturais e porosos ou não porosos) e métodos de imobilização (físicos ou químicos), sendo que não há um suporte ou técnica ideal que possa ser utilizada para todas as enzimas, e a escolha depende das características do biocatalisador e da reação catalisada por ela, além da finalidade do produto obtido (Coelho et al., 2008).

Neste contexto, o presente trabalho teve como objetivo imobilizar as lipases de Rhizopus oryzae, Aspergillus niger e Mucor javanicus, em suporte argila montmorillonita, empregando-se diferentes metodologias de imobilização (adsorção física e ligação covalente). Com base nos resultados de atividades hidrolíticas, de esterificação e rendimento de imobilização, os derivados imobilizados mais adequados serão selecionados para futura aplicação na catálise da síntese de triglicerídeos (TAG) dietéticos. Estes compostos são TAGs que sofreram modificações em suas cadeias de ácidos graxos, visando conferir diversos benefícios ao metabolismo e à saúde humana, podendo ser sintetizados por via química ou enzimática (Cabrita, 2012; Campos, 2010). Entretanto, a síntese enzimática, empregando lipases 1,3-específicas (Simões, 2011), é mais vantajosa pelo fato da reação ocorrer em condições de pressão em temperatura reduzidas, o que diminui o custo do processo.

\section{MATERIAIS E MÉTODOS}

\subsection{Materiais}

Os experimentos foram efetuados empregando preparações de lipases de diferentes fontes: Lipase de Rhizopus oryzae, Aspergillus niger e Mucor javanicus, gentilmente cedidas pela Prozyn (São Paulo, Brasil). Como suporte de imobilização foi empregada uma argila natural montmorillonita, gentilmente cedida pelo Laboratório de Peneiras Moleculares (LABPEMOL) da UFRN.

\subsection{Métodos}

Imobilização por adsorção física: $1 \mathrm{~g}$ de suporte foi embebido em $10 \mathrm{~mL}$ de hexano e mantido sob agitação (150rpm) em temperatura ambiente por $2 \mathrm{~h}$. Posteriormente, foram adicionados solução aquosa de PEG $1500(0,5 \mathrm{mg} / \mathrm{mL})$ e lipase na proporção de $250 \mathrm{mg}$ de enzima: 1g suporte: $200 \mu \mathrm{L}$ solução de PEG. O derivado imobilizado foi mantido em geladeira por 24 h e, então, filtrado e lavado com hexano (Paula, 2012). 
Imobilização por ligação covalente: $O$ suporte foi embebido em solução de glutaraldeído 2,5\% (v/v) na proporção 1:10 e mantido sob agitação por 1h. Após este período, o suporte foi lavado com água destilada e solução tampão de $\mathrm{pH}$ 8,0 sendo levado à estufa $\left(60^{\circ} \mathrm{C}\right)$ por $24 \mathrm{~h}$. Posteriormente, o processo de imobilização foi realizado de acordo com todas as etapas descritas em "Imobilização por adsorção física" (Paula et al., 2008).

Determinação da atividade enzimática de esterificação: A atividade de esterificação da enzima foi quantificada pelo consumo de ácido oleico $(12,6 \mathrm{~mL})$ e etanol $(2,4 \mathrm{~mL})$, de acordo com metodologia descrita por Pinto et al. (2014).

Determinação de atividade hidrolítica: Foi determinada pelo método de retrotitulação, empregando-se emulsão de azeite de oliva (Paula, 2012).

Rendimento de imobilização: A rendimento de imobilização foi calculada usando a Equação 1:

$$
n(\%)=\frac{\mathrm{U} \times 100}{\mathrm{U}_{0}}
$$

Em que: $\mathrm{U}_{\mathrm{o}}=$ unidades de atividade hidrolítica oferecidas para imobilização; $\mathrm{U}=$ unidades de atividade hidrolítica total presente no suporte.

\section{RESULTADOS E DISCUSSÃO}

\subsection{Imobilização por Adsorção Física}

Os resultados de atividade hidrolítica, de esterificação e rendimento de imobilização das lipases imobilizadas em argila montmorillonita por adsorção física são mostrados na Tabela 1.

Tabela 1- Atividade hidrolítica, de esterificação e rendimento de imobilização das diferentes lipases imobilizadas em argila montmorillonita por adsorção física

$\begin{array}{cccc}\text { Lipase imobilizada } & \begin{array}{c}\text { Atividade hidrolítica } \\ (\mathbf{U} / \mathrm{g})^{*}\end{array} & \begin{array}{c}\text { Atividade de } \\ \text { esterificação }(\mathbf{U} / \mathbf{g})\end{array} & \begin{array}{c}\text { Rendimento de } \\ \text { imobilização }(\%) *\end{array}\end{array}$

\begin{tabular}{lccc}
\hline Aspergillus niger & $545,42 \pm 55,21$ & 858,99 & $17,08 \pm 1,73$ \\
Rhizopus oryzae & $1325,02 \pm 54,10$ & 944,45 & $25,34 \pm 1,03$ \\
Mucor javanicus & $465,00 \pm 21,49$ & 975,12 & $23,70 \pm 1,09$ \\
\hline \multicolumn{2}{c}{ *média \pm desvio padrão }
\end{tabular}

Todos os derivados forneceram elevados valores de atividade hidrolítica. A lipase de Rhizopus oryzae apresentou o melhor resultado, uma vez que esta enzima possui, naturalmente, maior capacidade de efetuar a hidrólise de triglicerídeos comparada às outras. Isto pode ser comprovado ao se observar o resultado de atividade hidrolítica das lipases livres, 
as quais também foram quantificadas. A lipase de Rhizopus oryzae apresentou atividade de $23568,43 \pm 559,20 \mathrm{U} / \mathrm{g}$, sendo muito superior às das outras lipases, pois a de Aspergillus niger forneceu 13297,78 $\pm 535,64 \mathrm{U} / \mathrm{g}$, enquanto a de Mucor javanicus foi 8837,52 $\pm 665,52 \mathrm{U} / \mathrm{g}$. Com relação à atividade de esterificação, todos apresentaram valores semelhantes, o que indica que são capazes de realizar anexação de novos ácidos graxos na molécula de triacilglicerol de forma adequada.

O rendimento de imobilização apresentou bons resultados, semelhantes aos obtidos no trabalho realizado por Sudbrack (2012), o qual variou de $13 \%$ a $22 \%$ para o mesmo método e suporte de imobilização. Houve diferença significativa dos resultados das lipases de Aspergillus niger comparado aos de Rhizopus oryzae e Mucor javanicus. Esta diferença está relacionada à capacidade de interação da estrutura do suporte com as enzimas. Desta forma, as lipases que apresentaram maior rendimento possuem maior afinidade de interação com a argila montmorillonita e, como este composto tem a propriedade de inchamento, este resultado deve-se, adicionalmente, à capacidade de adsorção das enzimas tanto na superfície quanto no espaço interlamelar do suporte (Sudbrack, 2012).

\subsection{Imobilização por Ligação Covalente}

A Tabela 2 mostra os resultados obtidos da imobilização das diferentes lipases em argila montmorillonita por ligação covalente com glutaraldeído.

Tabela 2- Atividade hidrolítica, de esterificação e rendimento de imobilização das diferentes lipases imobilizadas em argila montmorillonita por ligação covalente

\begin{tabular}{|c|c|c|c|}
\hline Lipase & Atividade hidrolítica (U/g) & $\begin{array}{c}\text { Atividade de } \\
\text { esterificação (U/g) }\end{array}$ & $\begin{array}{c}\text { Rendimento de } \\
\text { imobilização }(\%)^{*}\end{array}$ \\
\hline
\end{tabular}

\begin{tabular}{cccc}
\hline Aspergillus niger & $422,46 \pm 77,85$ & 872,48 & $16,06 \pm 2,96$ \\
Rhizopus oryzae & $187,51 \pm 1,49$ & 929,38 & $3,79 \pm 0,03$ \\
Mucor javanicus & $297,65 \pm 86,62$ & 1270,98 & $12,28 \pm 3,57$ \\
\hline
\end{tabular}

*média \pm desvio padrão

Comparando-se os resultados obtidos aos apresentados na Tabela 1, pode-se observar uma redução nos valores de atividade hidrolítica. Esta queda foi mais acentuada empregandose a lipase de Rhizopus oryzae, o que refletiu na maior redução no rendimento de imobilização. Isso porque a atividade hidrolítica é o parâmetro utilizado para o cálculo do rendimento. Com relação à atividade de esterificação, a lipase de Mucor javanicus imobilizada por ligação covalente forneceu um resultado de aproximadamente $24 \%$ superior ao obtido empregando-se o método de adsorção física. Quanto aos demais biocatalisadores, não foram observadas variações significativas.

Pelo fato da ligação covalente proporcionar maior fixação da enzima ao suporte, esperava-se que houvesse um aumento do rendimento de imobilização, porém, isto não ocorreu. Estes resultados podem ser melhor compreendidos quando se analisa a estrutura 
química do agente de ativação glutaraldeído. Trata-se de um agente bifuncional, com capacidade de se ligar aos grupamentos $-\mathrm{OH}$ da superfície do suporte. Considerando-se que a argila empregada no presente trabalho possui estrutura laminar, o agente bifuncional pode ter se ligado aos grupamentos interlamelares e, desta forma, a ligação suporte-lipase ocorreu de forma reduzida, ou seja, menor quantidade de biocatalisador foi imobilizado no suporte. Além disso, pode ainda ter ocorrido uma dificuldade de acesso do substrato da hidrólise (triglicerídeos) ao sítio ativo da enzima, por conta do impedimento estérico ocasionado pela ligação do agente de ativação (glutaraldeído) à lipase imobilizada. Isto parece não ter ocorrido com o substrato da esterificação (ácidos graxos), a qual apresentou bons resultados. As diferenças de resultados de rendimentos e atividades podem estar relacionadas a forma de exposição deste sítio ativo após a imobilização, ficando mais, ou menos expostos, dependendo da lipase empregada (Mateo et al., 2007). Assim, na futura aplicação na reação de acidólise para síntese do TAG dietético, será necessário que o derivado imobilizado seja capaz de hidrolisar o TAG e, posteriormente, anexar novos ácidos graxos de forma adequada. Desta forma, o método de imobilização por adsorção física foi selecionado para ser empregado nas próximas etapas.

\section{CONCLUSÃO}

A imobilização das lipases em argila montmorillonita por adsorção física apresentou resultados muito bons e promissores, comparada à metodologia de ligação covalente utilizando glutaraldeído, o que é interessante, principalmente para a indústria, por ser um processo mais simples e econômico. Além disto, as lipases de Rhizopus oryzae e Mucor javanicus imobilizadas por este método (adsorção física) foram as que obtiveram os melhores desempenhos, e que, futuramente, serão aplicadas nas reações de acidólise para síntese de triglicerídeos (TAG) dietéticos em reator batelada. Assim, o presente trabalho pôde contribuir para o desenvolvimento de tecnologias nacionais de processos enzimáticos, além de mostrar o grande potencial da aplicação de suportes alternativos para imobilização de lipases comerciais.

\section{AGRADECIMENTOS}

Os autores agradecem à Fundação de Amparo à Pesquisa do Estado de São Paulo (FAPESP) por apoiar a pesquisa (Processo 2016/13106-0) e torná-la uma realidade. À Novozymes A/S (Bagsvaerd, Denmark) e à Prozyn (São Paulo, Brasil), pela doação dos biocatalisadores.

\section{REFERÊNCIAS}

AIRES-BARROS, M. R.; FERNANDES, P. Imobilização dos biocatalisadores. In: CABRAL, J. M. S.; AIRES-BARROS, M. R.; GAMA, M. Engenharia enzimática. Lisboa: Lidel, 2003. p. $121-140$.

CABRITA, P. A. R. N. Produção de triacilgliceróis estruturados catalisada por lipases imobilizadas. 2012. 84 f. Tese (Doutorado em Engenharia Alimentar)- Instituto Superior de Agronomia, Universidade Técnica de Lisboa, Lisboa, 2012. 
CAMPOS, P. R. B. Acidólise enzimática de óleo de soja para obtenção de triacilgliceróis estruturados funcionais. 2010. 69 f. Dissertação (Mestrado em Ciências da Saúde)Universidade São Francisco, Bragança Paulista. 2010.

COELHO, M. A. Z.; SALGADO, A. M.; Ribeiro, B. D. Enzimas Imobilizadas. In: COELHO, M. A. Z.; SALGADO, A. M.; RIBEIRO, B. D. Tecnologia Enzimática. Rio de Janeiro: EPUB, 2008. p. $71-84$.

COLLA, L. M.; REINEHR, C. O.; COSTA, J. A. V. Aplicações e produção de lipases microbianas. CIATEC-UPF, v. 4, n. 2, p. 1-14, 2013.

MATEO, C.; PALOMO, J. M.; FERNANDEZ-LORENTE, G.; GUISAN, J. M.; FERNANDEZ-LAFUENTE, R. Improvement of enzyme activity, stability and selectivity via immobilization techniques. Enzyme and microbial technology, v. 40, n. 6, p. 1451-1463, 2007.

PAUlA, A. V.; MOREIRA, A. B.; BRAGA, L. P.; BRUNO, L. M. CASTRO, H. F. Comparação do desempenho da lipase de Candida rugosa imobilizada em suporte híbrido de polissiloxano-polivinilálcool empregando diferentes metodologias. Quim. Nova, v. 31, n. 1, p. 35-40, 2008.

PAUlA, A. V. Reestruturação da gordura de leite por interesterificação enzimática empregando lipase imobilizada: otimização das condições reacionais e operacionais. 2011. 212 f. Tese (Doutorado em Ciências) - Escola de Engenharia de Lorena, Universidade de São Paulo, Lorena/SP, 2012.

PINTO, M. C. C.; FREIRE, D. M. G; PINTO, J. C. Influence of the Morphology of CoreShell Supports on the Immobilization of Lipase B from Candida antarctica. Molecules, v. 19, n. 8, p. 12509-12530, 2014.

SIMÕES, T. F. S. Síntese enzimática de lípidos estruturados sucedâneos de gordura de leite humano, enriquecidos em ácidos gordos polinsaturados. 2011. 75 f. Dissertação (Mestrado em Biotecnologia dos Recursos Marinhos)- Instituto Politécnico de Leiria, Escola Superior de Turismo e Tecnologia do Mar, Peniche, 2011.

SUDBRACK, T. S. Imobilização de lipase em montmorilonita e aplicação em reações oleoquímicas. 2012. 66f. Dissertação (Mestrado em Química)- Instituto de Química, Universidade Federal do Rio Grande do Sul, Porto Alegre/RS, 2012. 